ORIGINAL ARTICLE

\title{
Ontogenic variation and effect of collection procedure on leaf biomechanical properties of Mediterranean seagrass Posidonia oceanica (L.) Delile
}

\author{
Carmen B. de los Santos ${ }^{1, *}$, Bárbara Vicencio-Rammsy ${ }^{2, *}$, Gilles Lepoint ${ }^{2}$, François Remy ${ }^{2}$, \\ Tjeerd J. Bouma ${ }^{3} \&$ Sylvie Gobert ${ }^{2}$ \\ 1 Interdisciplinary Centre of Marine and Environmental Research, University of Porto, Porto, Portugal \\ 2 Laboratory of Oceanology, MARE Centre, Université de Liège, Liège, Belgium \\ 3 Royal Netherlands Institute for Sea Research, Yerseke, The Netherlands
}

\section{Keywords}

Biomechanics; leaf age; non-destructive shoot method; plant ontogeny; seagrass; stiffness; strength.

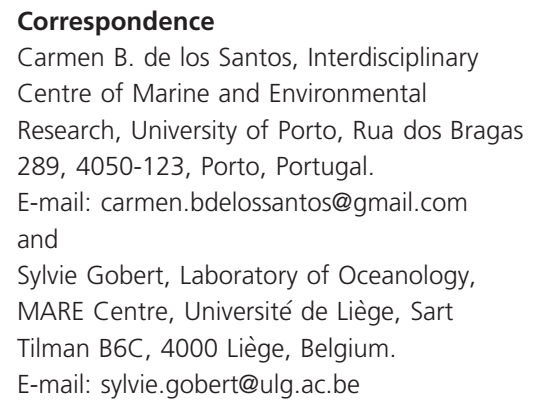

Carmen B. de los Santos, Interdisciplinary Centre of Marine and Environmental Research, University of Porto, Rua dos Bragas 289, 4050-123, Porto, Portugal.

E-mail: carmen.bdelossantos@gmail.com and

Sylvie Gobert, Laboratory of Oceanology, MARE Centre, Université de Liège, Sart Tilman B6C, 4000 Liège, Belgium. E-mail: sylvie.gobert@ulg.ac.be

*These authors contributed equally to this work.

Accepted: 31 August 2015

doi: 10.1111/maec.12340

\begin{abstract}
Leaf mechanical traits are important to understand how aquatic plants fracture and deform when subjected to abiotic (currents or waves) or biotic (herbivory attack) mechanical forces. The likely occurrence of variation during leaf ontogeny in these traits may thus have implications for hydrodynamic performance and vulnerability to herbivory damage, and may be associated with changes in morphologic and chemical traits. Seagrasses, marine flowering plants, consist of shoot bundles holding several leaves with different developmental stages, in which outer older leaves protect inner younger leaves. In this study we examined the long-lived seagrass Posidonia oceanica to determine ontogenic variation in mechanical traits across leaf position within a shoot, representing different developmental stages. Moreover, we investigated whether or not the collection procedure (classical uprooted shoot versus non-destructive shoot method: cutting the shoot without a portion of rhizome) and time span after collection influence mechanical measurements. Neither collection procedure nor time elapsed within $48 \mathrm{~h}$ of collection affected measurements of leaf biomechanical traits when seagrass shoots were kept moist in dark cool conditions. Ontogenic variation in mechanical traits in P. oceanica leaves over intermediate and adult developmental stages was observed: leaves weakened and lost stiffness with aging, while midaged leaves (the longest and thickest ones) were able to withstand higher breaking forces. In addition, younger leaves had higher nitrogen content and lower fiber content than older leaves. The observed patterns may explain fine-scale within-shoot ecological processes of leaves at different developmental stages, such as leaf shedding and herbivory consumption in P. oceanica.
\end{abstract}

\section{Introduction}

Seagrasses are rhizomatous marine flowering plants, with shoot bundles holding several leaves that are continuously produced by apical meristems according to a sequential alternate pattern (den Hartog 1970). This results in a shoot configuration containing different developmental stages, in which outer older leaves protect inner younger leaves, such that the relative leaf age within a shoot may be determined based on the leaf position. Leaf age is a source of variability for many aspects of seagrasses, such as morphometry (e.g. Caye \& Rossignol 1983), photosynthetic performance (e.g. Alcoverro et al. 1998), leaf growth (Sand-Jensen 1975), chemical composition (e.g. Gobert et al. 2005), epiphyte cover (e.g. Borum 1987; Casola et al. 1987) and grazing loss (e.g. Sand-Jensen 
et al. 1994). Some of these age-specific patterns in seagrass leaves are the result of processes and constraints at a cellular level related to leaf development and senescence. For instance, nitrogen dilution of old photosynthetic tissues by re-allocation of nitrogen to more productive zones of the leaf bundle causes loss of photosynthetic capacity and reduces nitrogen content in old leaves (Hemminga et al. 1999). Similarly, processes at the cellular level during leaf development may affect plant mechanical properties, such as leaf material strength or stiffness (Niklas 1992), which are important traits to understand how aquatic plants fracture and deform when subjected to abiotic (exposure to currents or waves) or biotic (herbivory attack) mechanical forces (Read \& Stokes 2006). For instance, material strength, along with leaf cross-sectional area, determines the force required to break a leaf for a given hydrodynamical force (Niklas 1992). Breaking force may be also associated with chemical traits such as carbon, nutrient and fiber content, which are important traits mediating herbivore preferences (Vergés et al. 2007a; de los Santos et al. 2012). Similarly, stiffness determines the resistance of the material to be deformed, so it is also important in the hydrodynamic performance of aquatic plants (Bouma et al. 2005). Thus, the likely occurrence of variation during leaf ontogeny in morphologic, mechanical and chemical traits may have ecologic implications for a plant's hydrodynamic performance and also for its vulnerability to herbivory damage (Read \& Stokes 2006).

The effect of leaf age on ecologic aspects of seagrass leaves is expected to be especially substantial in long-lived species such as Posidonia oceanica (L.) Delile, which displays a wide range of leaf ages (more than 200 days, Duarte 1991; Ott 1980) and of morphometry (Caye \& Rossignol 1983) within individual shoots. The ontogenic changes in seagrasses can be easily traced by measuring the mechanical traits over leaf sequential positions within a shoot, each position representing a different developmental stage. Mechanical testing involves the collection of leaves that are then submitted to forces until breakage occurs. Seagrass shoots have typically been collected with a portion of the rhizome for this purpose (e.g. de los Santos et al. 2012).

Endemic to the Mediterranean Sea, Posidonia oceanica meadows play a key role in marine productivity and are well acknowledged for the valuable ecosystem services that they provide (Vassallo et al. 2013), yet they are severely impacted by human activities (Marbà et al. 2014). Consequently, many legislation tools protects this species, such as the Habitat Directive, different international and regional conventions (Bern, Barcelona and Ramsar Conventions) and many National Red Lists in Mediterranean countries. Due to its protection status and its extremely low growth rate of the rhizome (mean horizontal elongation rate of $2 \mathrm{~cm} \cdot$ year $^{-1}$, Marbà \& Duarte 1998), methods of sampling P. oceanica should cause as little destruction as possible, avoiding the collection of the rhizome, while not compromising the research objective. The classical sampling method consists of uprooting $P$. oceanica shoots with the corresponding portion of rhizome. Alternatively, the non-destructive shoot method (NDSM) consists of cutting the shoot at the level of the sheath, with a study showing later regrowth of the shoot in $98 \%$ of cases (Gobert et al. 2012). The NDSM has been shown to be valid for measurements of trace metal contaminations, shoot phenology and leaf nutrient content (Gobert et al. 2012). This procedure, together with the time for which samples are stored before testing, may however imply loss of leaf water content and, consequently, could misestimate the values of the mechanical properties (Garnier et al. 2001).

In the present study, we aimed to (i) investigate if the collection procedure and the period of time that elapses between collection and testing may influence the measurements of mechanical properties (i.e. breaking force, strength and stiffness) of Posidonia oceanica leaves; (ii) determine the occurrence of ontogenic variation in leaf mechanical (breaking force, strength and stiffness), morphologic (length, width and thickness) and chemical (carbon, nitrogen and fiber contents) properties of P. oceanica; and (iii) examine the correlation of these traits. For these purposes we measured the traits in leaves at different positions within a shoot, representing young to old ontogenic stages, in plants collected either by the classical uprooted shoot method or by the NDSM and at 24 and $48 \mathrm{~h}$ after collection.

\section{Methods}

Sampling site and biological material

Shoots of Posidonia oceanica were sampled in Revellata Bay (Calvi, Corsica, France), near the Submarine and Oceanographic Research Station (STARESO; 42 $34^{\prime} 28.53^{\prime \prime} \mathrm{N}$, $8^{\circ} 43^{\prime} 26.15^{\prime \prime}$ E) in June 2013. This site consists of an extensive $P$. oceanica meadow covering about 180 ha up to $38 \mathrm{~m}$ depth (Bay 1984). Shoots were collected manually at random from a shallow meadow $(4.3 \mathrm{~m})$ by SCUBA diving, following the NDSM (i.e. cutting the shoot at the level of the sheath with a pair of scissors, and carefully tying the leaf bundle with a rubber band to maintain the leaf configuration within the shoot) and with a portion of rhizome, following the classical uprooted shoot method. For their transportation to the laboratory, seagrass shoots were laid out horizontally, wrapped completely in seawater-moistened tissue, placed in plastic bags and sealed to avoid des- 
iccation. Plastic bags were packed in an ice box with two small plastic ice blocks wrapped several times in tissue paper to maintain cool conditions during transportation by plane to the facilities of Utrecht University (The Netherlands) for testing of mechanical properties. Samples arrived within $24 \mathrm{~h}$ of collection.

\section{Leaf trait measurements}

Morphologic (leaf length, width and thickness), mechanical (breaking force, strength and stiffness) and biochemical traits (fiber, carbon and nitrogen contents) were measured in leaves from 41 vegetative shoots holding from four to seven leaves, with more than $60 \%$ of the shoots having five or six leaves. For the first set of samples, leaf traits were determined in 20 shoots within $24 \mathrm{~h}$ of collection (seven of them having been collected with the NDSM). For the second set, leaf traits were measured within $48 \mathrm{~h}$ of collection in 21 shoots (six of them having been collected with the NDSM) after having been kept moistened with tissue dampened with seawater in cool dark conditions $\left(15^{\circ} \mathrm{C}\right)$. In both sets of samples, all of the leaves within each shoot were carefully separated by their position and numbered from 1 (the youngest, most internal leaf) to the $i$ th outermost one (oldest leaf) in a discrete scaling of leaf age, representing a range of developmental stages. A total of 225 leaves was analysed: 41 leaves for each positions from 1 to 4,34 leaves for position 5, 20 for position 6 and seven leaves for position 7 . Leaf length $( \pm 0.1 \mathrm{~cm})$ was measured with a ruler for each leaf within the shoot, from the leaf tip to the junction with the sheath. Leaves from shoots collected by the classic method were additionally sorted into three different types of leaves (juvenile, intermediate and adult) according to Giraud (1979): adult leaves present two distinct regions (leaf blade and sheath), intermediate leaves have no sheath and juvenile leaves are shorter than $5 \mathrm{~cm}$. To avoid the confounding effects of age variability within the leaf and to limit epiphyte colonization, which both increase from the base to the leaf tip, a single fragment of $100 \mathrm{~mm}$ in length was excised per leaf from the junction between the blade and the sheath in the direction of the leaf tip. Epiphytes, which are generally less abundant on this part, were gently and carefully wiped off the leaves using tissue paper prior to measurements.

Width (digimatic caliper, Mitutoyo, 500 series, $\pm 0.01 \mathrm{~mm}$ ) and thickness (digital thickness gauge, Mitutoyo, model 547-300S, $\pm 0.01 \mathrm{~mm}$ ) were measured in each leaf fragment, and cross-sectional area $\left(\mathrm{mm}^{2}\right)$ was obtained as the product of leaf width and thickness considering a rectangular approximation. Tensile properties of Posidonia oceanica leaves were measured with a tensometer (Instron ${ }^{\circledR}$, model 5542, BLUEHILL ${ }^{\circledR}$ software v. 2.18, Norwood, MA, USA) using a 500-N load cell and pneumatic action grips (model 2712). Tests were conducted in leaf fragments parallel to their main axis after clamping them individually into the grips with the mounting $50 \mathrm{~mm}$ apart. The tissue fragments were then stretched at a constant velocity of $10 \mathrm{~mm} \cdot \mathrm{min}^{-1}$ while the displacement $(\mathrm{mm})$ and the force $(\mathrm{N})$ were recorded every $0.1 \mathrm{~s}$ until breakage. The breaking force $(\mathrm{N})$ and final displacement $(\mathrm{mm})$ were recorded at that time. Breaking strength $\left(\mathrm{N} \cdot \mathrm{mm}^{-2}\right)$ was then calculated as the breaking force per unit of initial cross-sectional area. This is a material property (i.e. size invariant) and determines the maximum stress, or force per unit of area, that the leaf may support before breaking. Young's modulus of elasticity or material stiffness $\left(\mathrm{N} \cdot \mathrm{mm}^{-2}\right)$, that is, the resistance to deformation, was calculated by taking the initial slope of the curve of applied force against displacement the initial length and cross-sectional area of the specimen.

After testing, leaf fragments were freeze dried and the dry biomass was pulverized in a mixer mill for biochemical analysis. Fiber content (percentage of dried biomass, $\%$ ) was measured in leaf fragments following the Van Soest method (Van Soest et al. 1991) with some small modifications (see de los Santos et al. 2012 for details). This procedure gives the neutral detergent fiber content as the difference in dry biomass after digestion of a sample (20-30 mg) in boiling neutral detergent for $1 \mathrm{~h}$, followed by repetitive washings of the pellet with distilled water, ethanol and acetone, and finally being oven-dried. In seagrasses, fiber content roughly represents the amount of cellulose and hemicellulose (Kuo \& den Hartog 2006). Nitrogen and carbon contents of leaf tissues (\% of dried biomass) were determined from 2 to $3 \mathrm{mg}$ of dried biomass using an elemental analyser (VarioMicro cube, Elementar ${ }^{\circledR}$, Elementar Analysensysteme GmbH, Hanau, Germany). Glycine was used as internal standard for calibration curves.

\section{Statistical analysis}

Data are presented as mean and 1 SEM. Within-shoot variation for each trait was calculated as the average of the co-efficient of variation calculated for each replicate. Linear mixed-effects models on $\log _{10}$-transformed data were used to test the effect of method, time and leaf position on each leaf traits. In this model, time, method, the interaction time-method and the leaf position were included as fixed factors, and replicate was included as a random factor. Linear mixed-effects models were fit by maximum likelihood and type III Wald $\chi^{2}$ tests were used to assess the significance of the fixed effects in the model. When the effect of any fixed factors was significant, 
homogenous groups were obtained from Tukey's multiple comparisons tests. Visual inspection of residual plots did not reveal any obvious deviation from homoscedasticity or normality in the linear models. Pearson's correlation co-efficient was used to test the degree of association between pairs of traits after pooling measurements for all leaf ranks and methods. Stepwise regression analysis was used to test which leaf traits best explained the leaf breaking force by constructing different models after elimination of traits and comparing them based on the Akaike information criterion (AIC; Akaike 1973; i.e. the lower the AIC, the better the model). The significance level was $\mathrm{P}<0.05$. Statistical analysis was carried with the $\mathrm{R}$ programming language R 3.0.3 (R Core Team, 2014).

\section{Results}

Mechanical traits were not affected by the sampling method or time from sampling (Fig. 1, linear mixedeffects model, $\mathrm{P}>0.05$ for fixed factors method, time and their interaction for all traits).

The effect of leaf position was significant for all mechanical, morphologic and chemical leaf traits (Fig. 2, linear mixed-effects model, $\mathrm{P}<0.05$ for fixed factor leaf position). The highest variation (co-efficient of variation) was found in morphologic traits $(31.1 \%$ and $32.2 \%$ in length and thickness, respectively, but $3.5 \%$ in width), followed by mechanical traits $(27.8 \%, 21.7 \%$ and $17.7 \%$ in breaking force, strength and stiffness, respectively) and chemical traits $(13.9 \%, 7.5 \%$ and $3.4 \%$ in nitrogen, fiber and carbon content, respectively). Maximum leaf length and thickness were reached in mid-aged leaves (positions 3 and 4, respectively) and then decreased linearly with age, while leaf width was nearly invariant with age, only differing in the innermost leaf (Fig. 2A-C). The youngest leaves in the sampled shoots were on average $50.5 \pm 3.4 \mathrm{~mm}$ in length ( $n=41$ leaves), and only one of them were classified as a 'juvenile leaf' (leaves length shorter than $5 \mathrm{~cm}$ ) according to Giraud (1979). In the studied range of leaf developmental stages, breaking force varied, giving a bell-shaped curve, with intermediate leaves (positions 3 and 4) resisting forces up to $30 \mathrm{~N}, c$. 1.5 times higher on average than both the older and the youngest leaves (Fig. 2D). The intermediate leaves were, in addition, the longest ones, having mean lengths of $72.8 \pm 2.5 \mathrm{~cm}$ (position 3) and $58.7 \pm 2.3 \mathrm{~cm}$ (position 4). Breaking strength, i.e. breaking force per unit of cross-section area, decreased linearly with leaf position by a factor of $c$. 1.6 , from $8.1 \pm 0.2 \mathrm{~N} \cdot \mathrm{mm}^{-2}$ in the innermost leaf to $5.0 \pm 0.6 \mathrm{~N} \cdot \mathrm{mm}^{-2}$ in the outermost leaf (Fig. 2E). The youngest leaves (positions 1 and 2) were clearly stiffer $\left(356-383 \mathrm{~N} \cdot \mathrm{mm}^{-2}\right)$ than the rest of the leaves (average stiffness of $296 \mathrm{~N} \cdot \mathrm{mm}^{-2}$, Fig. 2F). Regarding chemical leaf traits, nitrogen sharply decreased from

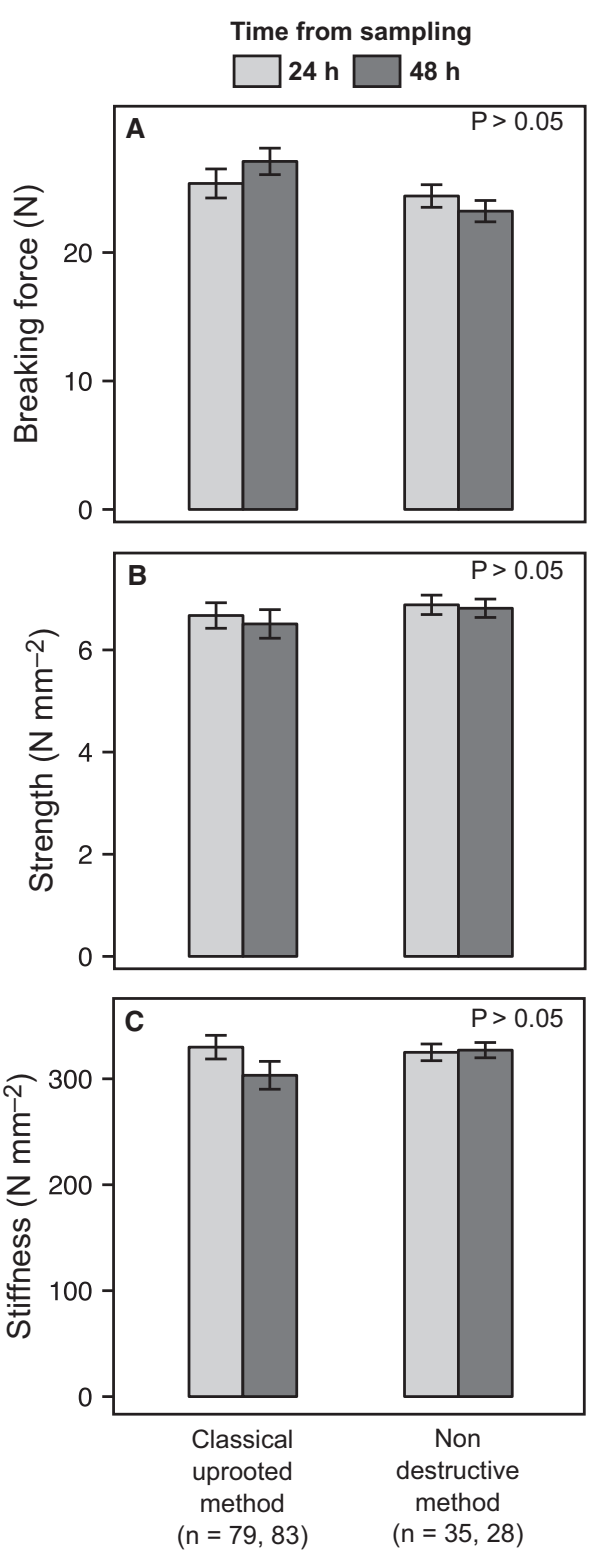

Fig. 1. Leaf mechanical traits by collection procedure and time elapsed after collection (mean \pm 1 SEM). Significant differences were not found among procedure, time of collection or their interaction (linear mixed-effects model, $P>0.05)$. Sample size $(n)$ in parentheses.

position 1 to the outer leaves (Fig. 2G), a variation that was reflected in an increasing C:N ratio with age (Fig. $2 \mathrm{H}$ ). Fiber content increased almost linearly from the three innermost leaves $(54.6 \%)$ to the outermost positions (57.8\%) (Fig. 2I). Carbon content decreased from leaf 1 $(32.6 \%)$ to leaves 2 and $3(31.8 \%)$ and then increased in the rest of the leaves $(32.9 \%$ ) (not shown in the figure, linear mixed-effects model, $\left.\chi^{2}=33.3, \mathrm{P}<0.001\right)$.

Pooling measurements among leaf ranks and methods, breaking force correlated positively and strongly with leaf 

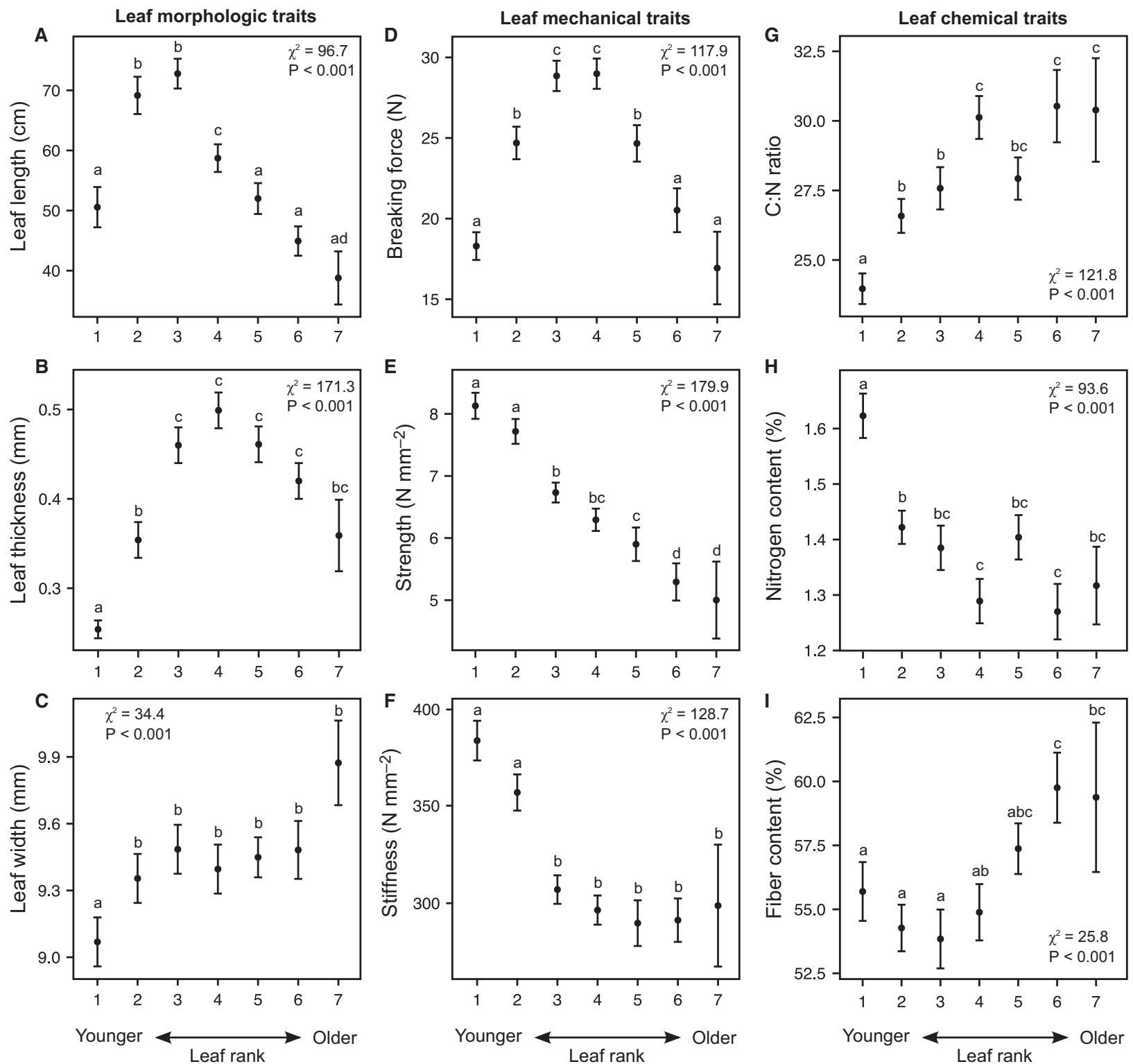

Fig. 2. Leaf traits by leaf position (mean \pm 1 SEM). Lower-case letters indicate different homogenous groups. Sample size: 41 leaves for positions 1-4, 34 leaves for position 5, 20 leaves for position 6 and seven leaves for position 7.

length and thickness (Fig. 3A,B), weakly to leaf width (Fig. 3C) and did not correlate with tensile strength (Fig. 3D). C:N ratio and fiber contents correlated to breaking force, such that stronger leaves presented higher $\mathrm{C}: \mathrm{N}$ ratios and lower fiber contents (Fig. 3E,F). In the stepwise regression analysis, the initial model was constructed with the whole array of traits (leaf length, thickness, width, tensile strength, fiber content, $\mathrm{C}: \mathrm{N}$ ratio and leaf rank). The exclusion of the fiber content improved the model to a slight extent (Table 1). Among the included traits, leaf thickness, strength and width were those with the highest importance in the model in terms of explaining the breaking force (Table 1).

\section{Discussion}

We initially expected that loss of turgescence of the leaves after cutting the shoots in the NDSM or after time had passed from collection could result in differences in mechanical properties. However, our study demonstrated that neither collection procedure nor time elapsed within $48 \mathrm{~h}$ from collection (while seagrass shoots were kept 

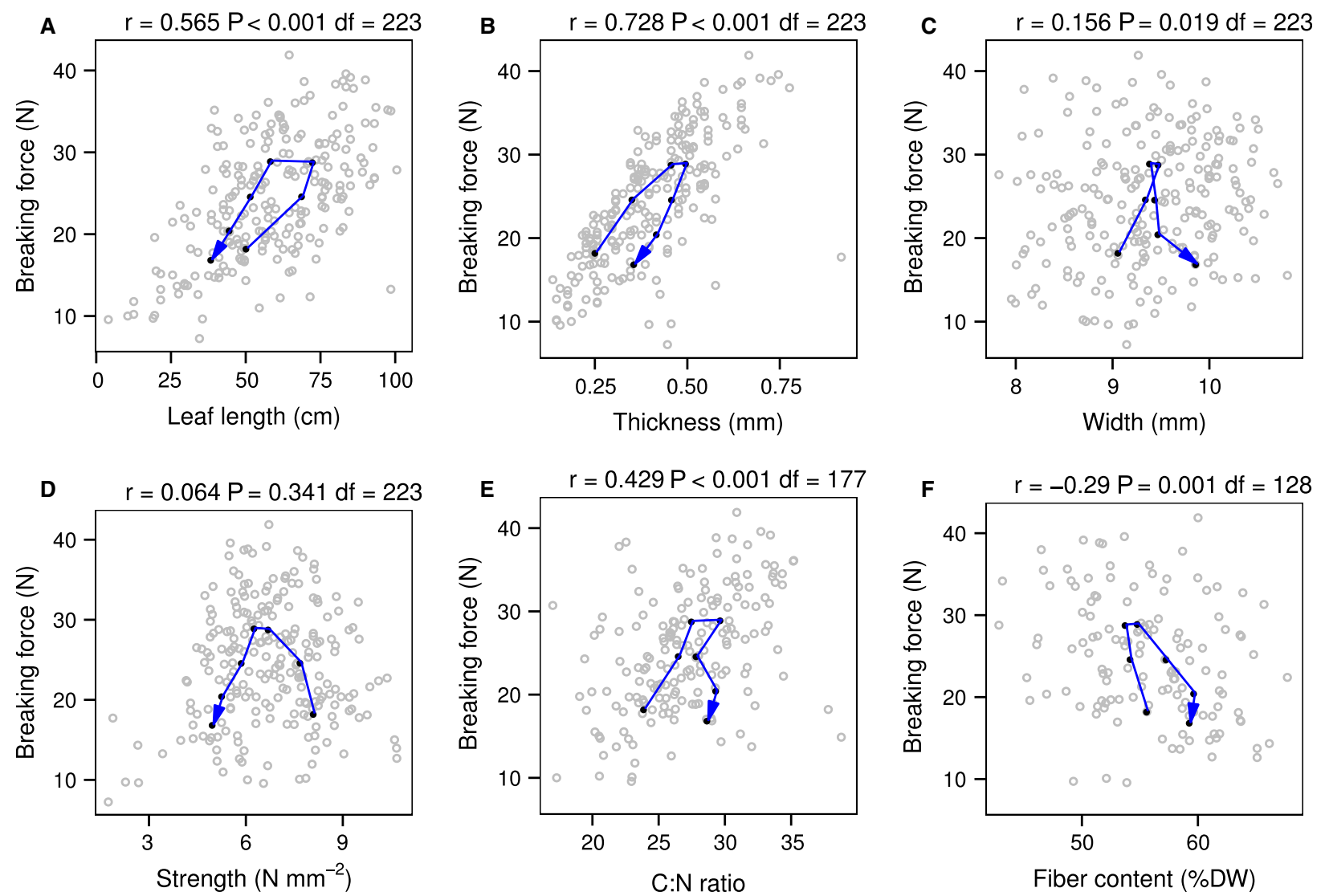

Fig. 3. Correlations among leaf traits showing the whole data set (gray open circles) and the average values for each leaf position (black closed circles). The blue arrow connects the average values from young to old rank positions. Pearson's correlation co-efficient ( $r$ ) is shown for each pair of traits with their significance $(P)$ and degrees of freedom (df).

moist in dark cool conditions) affected measurements of leaf biomechanical traits. These findings are in agreement with Koehl \& Wainwright (1985) who reported no significant difference between mechanical properties of fresh algae in specimens kept chilled in coolers for a day or two while being shipped. These results provide useful information for seagrass collection methods because mechanical properties are rarely measured in situ and some time normally elapses before samples are tested, especially when collected material has to be shipped to the destination laboratory.

As hypothesized, we observed significant ontogenic variation in mechanical traits in the long-lived species Posidonia oceanica. Over seven intermediate and adult developmental stages, leaves weakened and became less stiff with aging (from intermediate to adult leaves), while the highest breaking forces were attained in mid-aged leaves. In terrestrial plants, leaf stiffness normally increases as a leaf ages, which has been explained by developmental constraints in the cell walls during leaf development (Niklas 1992). Specifically, mechanical reinforcement is not an option for expanding leaves due to incompatibility with cell division and expansion; thus, cell walls of growing young tissues are ductile while older cell walls tend to be stiffer and more resilient (Niklas 1992; Read \& Stokes 2006). We found, however, that intermediate leaves were stiffer than adult leaves within a shoot. A plausible explanation is that we did not sample the complete spectrum of leaf age within a shoot of $P$. oceanica as juvenile expanding leaves were underrepresented in the collected shoots, probably because they were sampled during the season of maximum leaf elongation rate, when juvenile leaves are not very frequent (Alcoverro et al. 1995; Gobert 2002). Indeed, the only juvenile leaf (a leaf shorter than $5 \mathrm{~cm}$, according to Giraud 1979) measured from the sampled material was much more elastic $\left(197 \mathrm{~N} \cdot \mathrm{mm}^{-2}\right)$ and weaker $\left(6.5 \mathrm{~N} \cdot \mathrm{mm}^{-2}\right)$ than the mean values for the oldest leaf within the shoot (383 and $8.13 \mathrm{~N} \cdot \mathrm{mm}^{-2}$, respectively). Thus, cellular constraints likely occur also at early stages of $P$. oceanica leaf development. At the same time, the decrease in stiffness and strength with age from interme- 
Table 1. Summary of the stepwise regression analysis to select traits explaining the leaf breaking force. The first model (M1) includes all leaf traits (leaf length, thickness, width, tensile strength, fiber content, $\mathrm{C}: \mathrm{N}$ ratio and leaf rank) and shows the effect on Akaike information criterion (AIC) after eliminating each of them. The second model (M2) was constructed with traits according to the reduction in the AIC from the previous model (i.e. excluding the fiber content), but the exclusion of further traits did not improve the model.

\begin{tabular}{lrcc}
\hline model & df & residual deviance & AIC \\
\hline M1 (all traits) & 114 & 645.5 & 219.3 \\
fiber content & 1 & 655.8 & 219.2 \\
leaf rank & 1 & 678.6 & 223.4 \\
C:N ratio & 1 & 704.8 & 227.9 \\
length & 1 & 771.9 & 239.1 \\
width & 1 & 867.2 & 253.3 \\
strength & 1 & 1690.2 & 334.7 \\
thickness & 1 & 2951.5 & 402.7 \\
M2 (all traits - fiber content) & 115 & 655.8 & 219.2 \\
fiber content & 1 & 645.5 & 219.3 \\
leaf rank & 1 & 679.6 & 221.5 \\
C:N ratio & 1 & 747.4 & 233.2 \\
length & 1 & 794.9 & 240.7 \\
width & 1 & 894.9 & 255.1 \\
strength & 1 & 1697.9 & 333.2 \\
thickness & 1 & 3003.8 & 402.8 \\
\hline
\end{tabular}

diate to adult leaves may be due to the repetitive fatigue experienced by leaves during their lifespan because of continuous exposure to mechanical loads by water motion, as previously reported for macroalgae (Mach 2009). The age-specific pattern in breaking force (which is proportional to cross-section area and material strength) was parallel to leaf length and was mainly explained by the variation in leaf thickness, as indicated by the strong correlation of breaking force with leaf length and thickness, and by the importance of the latter trait in the regression model. The tight correlation between leaf length and breaking force has a twofold explanation. First, the short, still-expanding young leaves are soft (low strength) and thin, thus supporting low breaking forces. Second, the weakening and thinning of old leaves due to senescence processes and repetitive fatigue make them prone to break and deform easily; thus, the leaf breaks continuously at the tip and becomes shorter. The negative correlation between fiber content and material strength was unexpected because tensile strength is a property that is often correlated with the relative proportions and arrangement of structural components across species (e.g. Onoda et al. 2011). In our case, the negative correlation may be the result of the aging process within the same plant, i.e. leaves are reinforced as they age because of an increased allocation of fibers but, through senescence, repetitive mechanical fatigue may reduce their functionality, which may be reflected in a decrease in material strength. Given that our findings correspond to a single shallow meadow, further studies are needed to investigate the same mechanical patterns in plants collected at different sites and depths.

The reported variation in mechanical traits over plant ontogeny may have ecologic implications due to the different mechanical vulnerabilities of leaves within a shoot. In a seagrass shoot, the external or long internal leaves are probably those directly experiencing the mechanical loads imposed by water motion, as the inner short leaves are sheltered by the outer leaves. The weakening of seagrass leaves with age may be advantageous, either in shedding whole senescent leaves or in removing the apical parts of leaves, as old leaves, especially at the leaf tip, are normally covered with epiphytes (Casola et al. 1987), which may increase the drag forces experienced by leaves due to the larger area exposed to the flow (Koch et al. 2006). The intermediate leaves were the longest, thickest and strongest ones within the shoot in the present study. Although seagrass leaves bend and streamline with water flow so that drag forces are reduced (e.g. Bouma et al. 2005), the central leaves examined here presented a higher frontal area (which is proportional to leaf length due to the almost constant leaf width) in comparison to the short leaves within the same shoot, and thus experienced high drag forces. Their high breaking force is thus a way to tolerate the forces exerted on them by currents and waves, thus decreasing the risk of breakage (Puijalon et al. 2011).

These ontogenic patterns in leaf traits may have consequences for plant-herbivore interactions (Read \& Stokes 2006). In terrestrial plants, for instance, mature leaves suffer significantly less grazing damage than young leaves because the former are more mechanically resistant, thus being more difficult to bite, chew and digest than young leaves (Coley 1980). In addition, the high herbivory rate of young leaves is explained in terrestrial plants due to their greater nutritional value, because they generally have two to four times the nitrogen content of mature leaves (Kursar \& Coley 1991). Similarly, we found that nitrogen content and C: $\mathrm{N}$ ratio decreased with leaf age, as repeatedly reported in Posidonia oceanica (e.g. Alcoverro et al. 1998; Peirano et al. 2001), which is explained by a leaching of nutrients or by their translocation from old tissues before being lost (Hemminga et al. 1999; Lepoint et al. 2002) and by the high content of amino acids in young leaves (Invers et al. 2002). Preferential foraging behavior of herbivores consuming different developmental stages of $P$. oceanica leaves has been explained by nutritional quality, chemical defenses, epiphyte load and fracture properties (e.g. Peirano et al. 2001; Vergés et al. 2007a,b; Prado et al. 2010; Prado \& Heck 2011; and references therein). The reported varia- 
tion in leaf mechanical resistance and nutritional quality (fiber content and C:N ratio) throughout plant development may contribute to understanding the fine-scale within-shoot variations in the consumption of P. oceanica by herbivores. Accordingly, it would be expected that the inner (less mechanically resistant and less fibrous) leaves, with higher nitrogen content, would be preferentially consumed by herbivores. Phenological studies have shown preferential grazing on certain P. oceanica leaf developmental stages, but without a clear pattern and varying with the season, depth and herbivore species. For instance, juvenile fish Sarpa salpa may feed preferentially on the intermediate or middle-aged (Cebrián et al. 1996), or adult leaves of the shoots (Peirano et al. 2001). By contrast, the sea urchin Paracentrotus lividus was found to attack leaves trapped by its spines without preference for any particular leaf age range (Cebrián et al. 1996), although Vergés et al. (2007a) showed a preference for inflorescences in this species, and Peirano et al. (2001) showed that sea urchins preferred adult leaves. Sand-Jensen et al. (1994) also showed a linear increase in area consumed with leaf position or age in $P$. oceanica. The preferential consumption of adult leaves has been explained by the growth of nutritionally rich algal epiphytes on old leaves (Peirano et al. 2001). The lower levels of consumption of less mechanically and more nutritional leaves within the shoot (i.e. young inner leaves) can be explained by the growth leaf patterns of seagrasses as a phenological strategy to reduce the risk of physical damage to inner leaves due to protection by outer leaves. Thus, the intermediate and oldest (i.e. the least nutritious) leaves within a shoot are more accessible to herbivores. By contrast, small grazers (such as mollusks) preferentially selected central leaves of the shoots and/or basal part of the leaves (both young tissues) in other seagrass species (Zostera marina and Cymodocea nodosa, Rueda et al. 2009, 2011), likely due to the lower fibre content of these leaf parts in comparision to older foliar tissues.

\section{Summary}

In conclusion, we have provided new information on methodological aspects of measuring mechanical properties in seagrass leaves, specifically the validity of sampling the shoot without the rhizome and measuring various properties within $48 \mathrm{~h}$ of collection. In addition, this study has provided evidence of previously unexplored ontogenetic variation in leaf mechanical traits of seagrasses, showing that leaves of Posidonia oceanica weaken and become less stiff with aging (from intermediate to adult leaves), in parallel with leaf thinning, nitrogen decline and fiber reinforcement. These patterns at the shoot scale are fundamental to understanding ecologic processes at small scales and also for upscaling studies in which the leaf properties are used to explain ecologic processes at the meadow or ecosystem scales. Further studies are needed to extend our findings to different $P$. oceanica meadows, in particular those with different depth gradients and levels of exposure to mechanical disturbance.

\section{Acknowledgements}

B.V.R. was supported by the STARECAPMED project (STAtion of Reference and rEsearch on Change of local and global Anthropogenic Pressures on Mediterranean Ecosystems Drifts) which was funded by the Territorial Collectivity of Corsica and by the French Water Agency (PACA, Provence-Alpes-Côte d'Azur, and Corsica regions). We thank the STARESO staff for the facilities during the sampling. Thanks also to H.J. During and G.P. Verduyn (University of Utrecht) for facilitating access to the Instron ${ }^{\circledR}$ testing machine, and to $\mathrm{R}$. Biondo for help with the chemical analyses at the Université de Liege. We are also grateful to two anonymous reviewers for their constructive comments on the early version of the manuscript. This is Marine Reseach Centre (MARE) publication number MARE-302.

\section{References}

Akaike H. (1973) Information theory and an extension of the maximum likelihood principle. Proceedings 2nd International Symposium on Information Theory: 267-281.

Alcoverro T., Duarte C.M., Romero J. (1995) Annual growth dynamics of Posidonia oceanica: contribution of large-scale versus local factors to seasonality. Marine Ecology Progress Series, 120, 203-210.

Alcoverro T., Manzanera M., Romero J. (1998) Seasonal and age-dependent variability of Posidonia oceanica (L.) Delile photosynthetic parameters. Journal of Experimental Marine Biology and Ecology, 230, 1-13.

Bay D. (1984) A field study of the growth dynamics and productivity of Posidonia oceanica (L.) Delile in Calvi Bay, Corsica. Aquatic Botany, 20, 43-64.

Borum J. (1987) Dynamics of epiphyton on eelgrass (Zostera marina L.) leaves: relative roles of algal growth, herbivory, and substratum turnover. Limnology \& Oceanography, 32, 986-992.

Bouma T.J., De Vries M.B., Low E., Peralta G., Tánczos I.C., van de Koppel J., Herman P.M.J. (2005) Trade-offs related to ecosystem engineering: a case study on stiffness of emerging macrophytes. Ecology, 86, 2187-2199.

Casola E., Scardi M., Mazzella L., Fresi E. (1987) Structure of the epiphytic community of Posidonia oceanica leaves in a shallow meadow. Marine Ecology, 8, 285-296. 
Caye G., Rossignol M. (1983) Etude des variations saisonnières de la croissance des feuilles et des racines de Posidonia oceanica. Marine Biology, 75, 79-88.

Cebrián J., Duarte C.M., Marbà N., Enríquez S., Gallegos M., Olesen B. (1996) Herbivory on Posidonia oceanica: magnitude and variability in the Spanish Mediterranean. Marine Ecology Progress Series, 130, 147-155.

Coley P.D. (1980) Effects of leaf age and plant life history patterns on herbivory. Nature, 284, 545-546.

Duarte C.M. (1991) Allometric scaling of seagrass form and productivity. Marine Ecology Progress Series, 77, 289-300.

Garnier E., Shipley B., Roumet C., Laurent G. (2001) A standardized protocol for the determination of specific leaf area and leaf dry matter content. Functional Ecology, 15, 688-695.

Giraud G. (1979) Sur une méthode de mesure et de comptage des structures foliaires de Posidonia oceanica (Linnaeus) Delille. Bulletin Musée Histoire Naturelle Marseille, 39, $33-39$.

Gobert S. (2002) Variations spatiale et temporelle de l'herbier à Posidonia oceanica (L.) Delile. $\mathrm{PhD}$ dissertation, Université de Liège, Belgium.

Gobert S., Lejeune P., Lepoint G., Bouquegneau J.-M. (2005) C, N, P concentrations and requirements of flowering Posidonia oceanica. Hydrobiologia, 533, 253-259.

Gobert S., Lejeune P., Chéry A., Boissery P., Sartoretto S., Andral B., Lepoint G., Richir J. (2012) Assessment of the ecological status of Posidonia oceanica meadow with a no destructive shoot method. Proceedings 3rd Mediterranean Seagrass Workshop 2012: 18 pp.

den Hartog C. (1970) The Sea-Grasses of the World. NorthHolland Publishing Company, Amsterdam, London: 241 pp.

Hemminga M., Marbà N., Stapel J. (1999) Leaf nutrient resorption, leaf lifespan and the retention of nutrients in seagrass systems. Aquatic Botany, 65, 141-158.

Invers O., Pérez M., Romero J. (2002) Seasonal nitrogen speciation in temperate seagrass Posidonia oceanica (L.) Delile. Journal of Experimental Marine Biology and Ecology, 273, 219-240.

Koch E.W., Ackerman J.D., Verduin J., van Keulen M. (2006) Fluid dynamics in seagrass ecology-from molecules to ecosystems. In: Larkum A.W.D., Orth R.J., Duarte C.M. (Eds), Seagrasses: Biology, Ecology and Conservation. Springer, The Netherlands: 193-225.

Koehl M.A.R., Wainwright S.A. (1985) Biomechanics. In: Littler M.L., Littler D.S. (Eds), Handbook of Phycological Methods. Ecological Field Methods: Macroalgae. Cambridge University Press, Cambridge: 291-313.

Kuo J., den Hartog C. (2006) Seagrass morphology, anatomy, and ultrastructure. In: Larkum A.W.D., Orth R.J., Duarte C.M. (Eds), Seagrasses: Biology, Ecology and Conservation. Springer, The Netherlands: 51-87.

Kursar T.A., Coley P.D. (1991) Nitrogen content and expansion rate of young leaves of rain forest species: implications for herbivory. Biotropica, 23, 141-150.
Lepoint G., Defawe O., Gobert S., Dauby P., Bouquegneau J.-M. (2002) Experimental evidence for $\mathrm{N}$ recycling in the leaves of the seagrass Posidonia oceanica. Journal of Sea Research, 48, 173-179.

Mach K.J. (2009) Mechanical and biological consequences of repetitive loading: crack initiation and fatigue failure in the red macroalga Mazzaella. Journal of Experimental Biology, 212, 961-976.

Marbà N., Duarte C.M. (1998) Rhizome elongation and seagrass clonal growth. Marine Ecology Progress Series, 174, 269-280.

Marbà N., Díaz-Almela E., Duarte C.M. (2014) Mediterranean seagrass (Posidonia oceanica) loss between 1842 and 2009. Biological Conservation, 176, 183-190.

Niklas K.J. (1992) Plant Biomechanics: An Engineering Approach to Plant Form and Function. University of Chicago Press, Chicago: 622.

Onoda Y., Westoby M., Adler P.B., Choong A.M., Clissold F.J., Cornelissen J.H., Díaz S., Dominy N.J., Elgart A., Enrico L., Fine P.V.A., Howard J.J., Jalili A., Kitajima K., Kurokawa H., McArthur C., Lucas P.W., Markesteijn L., Pérez-Harguindeguy N., Poorter L., Richards L., Santiago L.S., Sosinki E.E. Jr, Van Bael S.A., Warton D.I., Wright I.J., Wroght S.J., Yamashita N. (2011) Global patterns of leaf mechanical properties. Ecology Letters, 14, 301-312.

Ott J.A. (1980) Growth and production in Posidonia oceanica (L.) Delile. Marine Ecology, 1, 47-64.

Peirano A., Niccolai I., Mauro R., Bianchi C.N. (2001) Seasonal grazing and food preference of herbivores in a Posidonia oceanica meadow. Scientia Marina, 65, 367-374.

Prado P., Heck K. (2011) Seagrass selection by omnivorous and herbivorous consumers: determining factors. Marine Ecology Progress Series, 429, 45-55.

Prado P., Alcoverro T., Romero J. (2010) Influence of nutrients in the feeding ecology of seagrass (Posidonia oceanica L.) consumers: a stable isotopes approach. Marine Biology, 157, 715-724.

Puijalon S., Bouma T.J., Douady C.J., van Groenendael J., Anten N.P., Martel E., Bornette G. (2011) Plant resistance to mechanical stress: evidence of an avoidance-tolerance trade-off. New Phytologist, 191, 1141-1149.

R Core Team (2014) R: A Language and Environment for Statistical Computing. R Foundation for Statistical Computing, Vienna, Austria. http://www.R-project.org/.

Read J., Stokes A. (2006) Plant biomechanics in an ecological context. American Journal of Botany, 93, 1546-1565.

Rueda J.L., Salas C., Marina P., Urra J. (2009) Herbivory on Zostera marina by the gastropod Smaragdia viridis. Aquatic Botany, 90, 253-260.

Rueda J.L., Salas C., Gofas S. (2011) Contrasting shell morphology, ingestion and grazing preferences in the neritid gastropod Smaragdia viridis (L.) on two seagrass species. Journal of Sea Research, 66, 222-230.

Sand-Jensen K. (1975) Biomass, net production and growth dynamics in an eelgrass (Zostera marina L.) population in Vellerup Vig, Denmark. Ophelia, 14, 185-201. 
Sand-Jensen K., Jacobsen D., Duarte C.M. (1994) Herbivory and resulting plant damage. Oikos, 69, 545-549.

de los Santos C.B., Brun F.G., Onoda Y., Cambridge M.M., Bouma T.J., Vergara J.J., Pérez-Lloréns J.L. (2012) Leaffracture properties correlated with nutritional traits in nine Australian seagrass species: implications for susceptibility to herbivory. Marine Ecology Progress Series, 458, 89-102.

Van Soest P., Robertson J., Lewis B. (1991) Methods for dietary fiber, neutral detergent fiber, and nonstarch polysaccharides in relation to animal nutrition. Journal of Dairy Sciences, 74, 3583-3597.
Vassallo P., Paoli C., Rovere A., Montefalcone M., Morri C., Bianchi C.N. (2013) The value of the seagrass Posidonia oceanica: a natural capital assessment. Marine Pollution Bulletin, 75, 157-167.

Vergés A., Becerro M.A., Alcoverro T., Romero J. (2007a) Variation in multiple traits of vegetative and reproductive seagrass tissues influences plant-herbivore interactions. Oecologia, 151, 675-686.

Vergés A., Becerro M.A., Alcoverro T., Romero J. (2007b) Experimental evidence of chemical deterrence against multiple herbivores in the seagrass Posidonia oceanica. Marine Ecology Progress Series, 343, 107-114. 